\title{
A reversible and highly selective two-photon fluorescent "on-off-on" probe for biological Cu2+ detection
}

Hui Wang, Bin Fang, Le Zhou, Di Li, Lin Kong, Kajsa Uvdal and Zhang-J un Hu

The self-archived postprint version of this journal article is available at Linköping University Institutional Repository (DiVA):

http:/ / urn.kb.se/ resolve?urn=urn:nbn:se:liu:diva- 147380

N.B.: When citing this work, cite the original publication.

Wang, H., Fang, B., Zhou, Le, Li, Di, Kong, L., Uvdal, K., Hu, Z., (2018), A reversible and highly selective two-photon fluorescent "on-off-on" probe for biological Cu2+detection, Organic and biomolecular chemistry, 16(13), 2264-2268. https:// doi.org/10.1039/ c8ob00257f

Original publication available at:

https:// doi.org/ 10.1039/ c8ob00257f

Copyright: Royal Society of Chemistry

http:// www.rsc.org/ 


\title{
Journal Name
}

\section{ARTICLE}

\section{A reversible and highly selective two-photon fluorescence "on-off- on" probe for biological $\mathrm{Cu}^{2+}$ detection}

Received 00th January 20xx, Accepted 00th January 20xx

DOI: $10.1039 / x 0 x \times 00000 x$

www.rsc.org/

\begin{abstract}
Hui Wang a,t, ${ }^{\text {, }}$, Bin Fang ${ }^{\mathrm{c},}$, Le Zhou ${ }^{\mathrm{a}}$, Di Li ${ }^{\mathrm{a}}$, Lin Kong ${ }^{\mathrm{c}}$, Kajsa Uvdal, ${ }^{\mathrm{b}}$ Zhangjun $\mathrm{Hu}^{\mathrm{b}}$
Two-photon active probe for physiological copper $\left(\mathrm{Cu}^{2+}\right)$ is expected to play an important role in the process of biological metabolism. Herein, a novel Schiff base derivative (E)-2,2'-((4-((4- (diethylamino) -2-hydroxybenzylidene) amino) phenyl) azanediyl) bis(ethan-1-ol) (L) with remarkable two-photon activity was developed and synthetically investigated. L presentes high selectivity and sensitivity for sensing $\mathrm{Cu}^{2+}$ in ethanol/HEPES buffer (v/v, 1:1), accompanying with the fluorescence switching "off" and subsequently "on" in the addition of EDTA. The mechanism for the detection of $\mathrm{Cu}^{2+}$ is further analyzed according to ${ }^{1} \mathrm{HNMR}$ titration, mass spectra and theoretical calculations. Furthermore, since the probe $\mathbf{L}$ possesses well photophysical properties, excellent biocompatibility and low cytotoxicity, it is successfully applied to tracking $\mathrm{Cu}^{2+}$ in the cellular endoplasmic reticulum by two-photon fluorescence imaging, exhibiting its potential value of practical applications in biological systems.
\end{abstract}

\section{Introduction}

Recently, development fluorescent chemosensors for transition metal ions has been attached considerable attentions due to their potential applications in chemical and biological processes ${ }^{1-5}$. In human body, $\mathrm{Cu}^{2+}$, as the third most abundant transition metal ion, plays important roles in biological systems, and keeping its appropriate homeostasis for the growth, development and fitness of living organisms ${ }^{6-8}$. However, abnormal level of $\mathrm{Cu}^{2+}$ in the human body causes severe neurological diseases such as Parkinson's disease and Alzheimer's disease 9-11. Moreover, copper pollution is becoming more widespread attributed to the increasing dosage of $\mathrm{Cu}$-containing

\footnotetext{
a. Department of Chemistry, Anhui provincial engineering research center for polysaccharide drugs, Wannan Medical college, Wuhu, 241002, P.R. China

b. Division of Molecular Surface Physics \& Nanoscience, Department of Physics, Chemistry and biology (IFM), Linköing University, 58183, Linköing, Sweden c. Department of Chemistry, Key Laboratory of Functional Inorganic Material Chemistry of Anhui Province, Anhui Univeristy, Hefei 230601, P.R.China + Corresponding author. Tel: +86-551-63861227

Email address: wanghias@126.com
}

materials in industry and agriculture. Consequently, the detection of $\mathrm{Cu}^{2+}$ in environment and biological samples becomes essential.

So far, many $\mathrm{Cu}^{2+}$ fluorescent probes have attracted great concern because of their high sensitivity and selectivity ${ }^{12-23}$. However, most of the designed probes are only available for one-photon fluorescence microscopy (1PM) with short excitation wavelengths and suffering from background interference. Thus, how to effectively track $\mathrm{Cu}^{2+}$ in biological systems with low tissue autofluorescence and photo-damage still remains challenge. As an alternative, two-photon microscopy (2PM), a powerful imaging tool for biomedical research, exhibits remarkable advantages over 1PM, including increased penetration ability, reduced photodamage and photobleaching ${ }^{24}$. Recently, Tian's group ${ }^{25}$ presented a reversible two-photon (2P) fluorescence probe (HL) for $\mathrm{Cu}^{2+}$ in HEPES buffer. In that work, the terminated quaternary ammonium salt moieties in the probe were supposed to be the main contributions to the mitochondria targeting ability of HL. To some extent, it means that the 
varied terminated moieties possibly lead to different specificity. Herein, a novel Schiff-base based fluorescent probe with hydroxyl moieties was then synthesized according to the literature ${ }^{26}$, as well as the similar sensing behaviours towards $\mathrm{Cu}^{2+}$ were expected. 2,2'-((4aminophenyl) azanediyl)diethanol was readily used to react with 4-(diethylamino)-2-hydroxybenzaldehyde to generate the proposed Schiff-base compound (L). The further studies demonstrated that $\mathbf{L}$ could selectively coordinate with $\mathrm{Cu}^{2+}$ with a distinct fluorescence quenching and subsequently a fluorescence recovering by the addition of EDTA. Furthermore, probe $\mathbf{L}$ exhibited suitable 2PA property, which could track $\mathrm{Cu}^{2+}$ in cellular endoplasmic reticulum with good photo-stability, offering a powerful tool for tracking $\mathrm{Cu}^{2+}$ in biological systems.

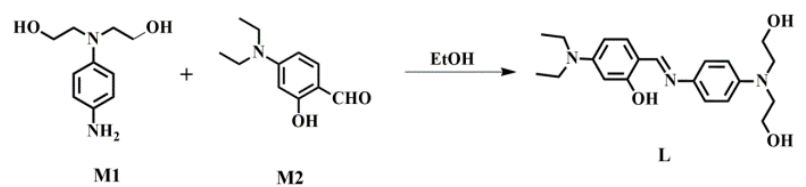

Scheme 1 The synthetic route for probe $\mathbf{L}$.

\section{Synthesis of $L$}

A mixture of 2,2'-((4-aminophenyl)azanediyl)bis(ethan1-ol) (M1) ${ }^{27}$ (0.39 g, 2 mmol) and 4-(diethylamino)-2hydroxybenzaldehyde (M2) (0.40 g, 2 mmol) were dissolved in $50 \mathrm{~mL}$ dry ethanol, and then added two drops glacial acetic acid, refluxed for $12 \mathrm{~h}$. The mixture was cooled to room temperature and filtered, washed twice with ethanol. The crude product was recrystallized with acetonitrile. Yield: $80 \%$. ${ }^{1} \mathrm{H}-\mathrm{NMR}\left(\mathrm{d}_{6}\right.$-DMSO, $400 \mathrm{MHz}$, ppm) $\delta: 13.96(\mathrm{~s}, 1 \mathrm{H}), 8.60(\mathrm{~s}, 1 \mathrm{H}), 7.23(\mathrm{t}, \mathrm{J}=14.1 \mathrm{~Hz}$, 1H), 7.18 (d, J = $8.4 \mathrm{~Hz}, 2 \mathrm{H}), 6.71(\mathrm{~d}, \mathrm{~J}=8.4 \mathrm{~Hz}, 2 \mathrm{H})$, 6.28 (t, J = $13.4 \mathrm{~Hz}, 1 \mathrm{H}), 6.04$ (s, 1H), 4.74 (s, 2H), 3.55 (d, J = 3.9 Hz, 4H), 3.42 (q, J=8.0 Hz, 4H), 3.36 (t, J=7.5 $\mathrm{Hz}, 4 \mathrm{H}$ ), 1.11 (t, J = $6.8 \mathrm{~Hz}, 6 \mathrm{H}$ ). ${ }^{13} \mathrm{C}-\mathrm{NMR}\left(\mathrm{d}_{6}\right.$-DMSO, $100 \mathrm{MHz}, \mathrm{ppm}) \delta$ : 162.8, 156.8, 150.6, 146.4, 136.1, 133.2, 121.5, 111.7, 108.8, 103.3, 97.0, 58.1, 53.3, 43.8,
12.53. IR $\left(\mathrm{cm}^{-1}\right)$ : 3177, 2968, 2924, 1613, 1519, 1432, 1357, 1303, 1240, 1130, 1065, 1004, 964, 921, 893, 825, 786, 677, 520. ESI-MS: $372.23[\mathrm{M}+1]^{+}$.

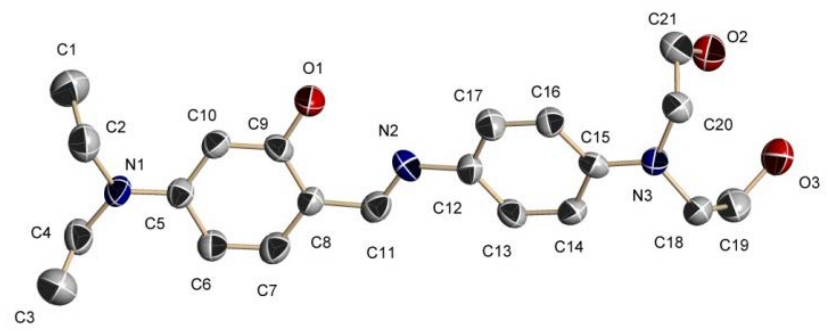

Figure 1 Crystal structure of L, all $\mathrm{H}$ atoms were omitted for clarity.

\section{Results and discussion}

\subsection{The synthesis of the probe $L$}

The probe $\mathbf{L}$ was synthesized by the simple and convenient process as displayed in Scheme 1. M1 was synthesized according to the reported literature ${ }^{27}$. Then, M1 was reacted with 4-(diethylamino)-2hydroxybenzaldehyde to give the probe $\mathbf{L}$ in ethanol. The probe $\mathbf{L}$ was characterized using ${ }^{1} \mathrm{H}$ NMR, ${ }^{13} \mathrm{C}$ NMR spectroscopy and mass spectrometry. The molecular structure of probe $\mathbf{L}$ was also confirmed by single-crystal X-ray diffraction analysis. The crystal data, selected bond lengths and angles were summarized in Table S1 and S2. As shown in Figure 1, the dihedral angle between the two benzene rings is $16.08^{\circ}$, which is linked by C12-N2 (1.417 $\AA)$, N2-C11 (1.282 $\AA)$ and C11-C8 (1.440 $\AA)$ with conjugated bond length. The planarity and the conjugated geometric configuration suggest that the probe $\mathbf{L}$ possesses highly $\pi$-electron delocalized system.

\subsection{Recognition of probe $L$ toward various metal ions}

The UV-vis absorption and one-photon fluorescence spectra of probe $\mathbf{L}$ towards various metal ions $\left(\mathrm{Ag}^{+}, \mathrm{Al}^{3+}\right.$, $\mathrm{K}^{+}, \mathrm{Ba}^{2+}, \mathrm{Bi}^{3+}, \mathrm{Ca}^{2+}, \mathrm{Cd}^{2+}, \mathrm{Co}^{2+}, \mathrm{Cr}^{3+}, \mathrm{Fe}^{3+}, \mathrm{Hg}^{2+}, \mathrm{Zn}^{2+}$, $\left.\mathrm{Li}^{2+}, \mathrm{Mg}^{2+}, \mathrm{Cu}^{2+}, \mathrm{Mn}^{2+}, \mathrm{Na}^{+}, \mathrm{Pb}^{2+}, \mathrm{Ni}^{2+}, \mathrm{Cu}^{+}\right)$in ethanol/HEPES buffer (v/v, 1:1) were depicted in Figure 2. As displayed in Figure 2a, the UV-vis absorption 
spectra of $\mathbf{L}(12.5 \mu \mathrm{M})$ exhibited one absorption band at $440 \mathrm{~nm}$. When adding the above metal ions (4 equiv.) respectively, only $\mathrm{Cu}^{2+}$ gave a remarkable response with a new absorption peak appearing at $390 \mathrm{~nm}$, which demonstrated the selective binding affinity of $\mathbf{L}$ toward $\mathrm{Cu}^{2+}$. In addition, strong spectral response of $\mathbf{L}$ towards $\mathrm{Cu}^{2+}$ was also determined in the fluorescence titration experiments. L displayed 8.5-fold decrease of fluorescence intensity at $528 \mathrm{~nm}$, whereas no obvious spectral changes in the presence of other metal ions (Figure 2b). The reason can be explained by the fact that $\mathrm{Cu}^{2+}$ has quenching capabilities due to its unfilled $\mathrm{d}$ shell and paramagnetic nature especially in aqueous media. Due to the unfilled d orbital of $\mathrm{Cu}^{2+}$, after being chelated by compound $\mathbf{L}$, the $\mathrm{d}$ d transitions of the $\mathbf{L}-\mathrm{Cu}$ assemble would be largely prohibited with the lowest energy, leading to luminescence quenching ${ }^{28}$.
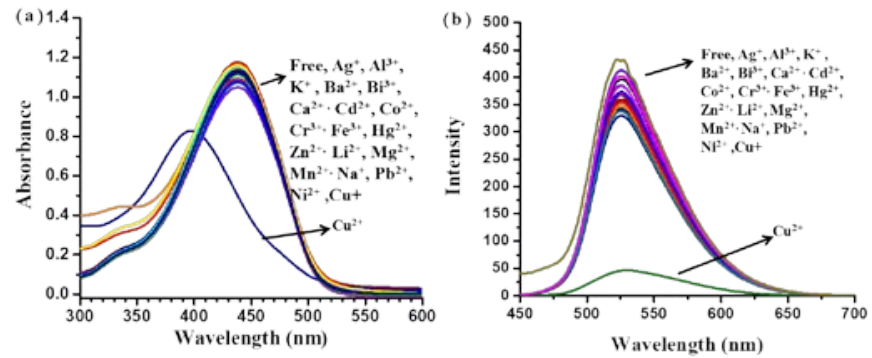

Figure 2 UV-vis absorption (a) and one-photon fluorescence (b) spectra of $L$ ( 12.5 $\mu \mathrm{M}$ ) in the presence of (4 equiv.) different metal ions in ethanol/HEPES buffe $(\mathrm{pH}=7.42)(\mathrm{v} / \mathrm{v}, 1: 1)$

Anti-interference experiment was then carried out to investigate the interferences of different metal ions on the $\mathrm{Cu}^{2+}$ recognition of $\mathbf{L}$. As shown in Figure S1, the competitive metal ions failed to cause remarkable fluorescence quenching of $\mathbf{L}$ except the subsequent addition of $\mathrm{Cu}^{2+}$. Taken together, these commonly coexisting metal ions do not interfere with "on-off” fluorescent response of $\mathbf{L}$ for detecting $\mathrm{Cu}^{2+}$.
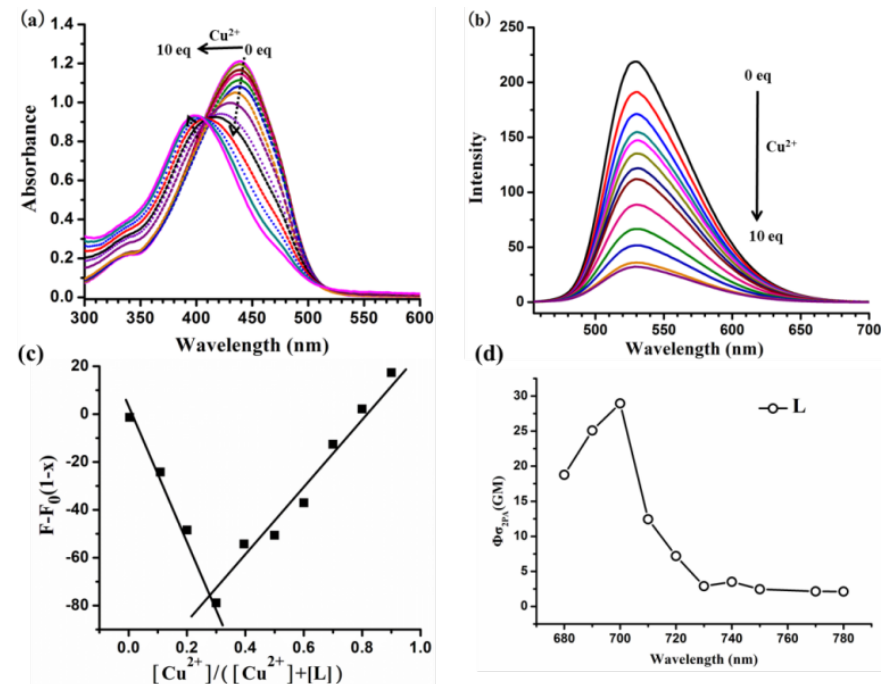

Figure 3 UV-vis absorption spectra (a) and fluorescence spectra of $\mathbf{L}(12.5 \mu \mathrm{M})$ upon the addition of $\mathrm{Cu}^{2+}(0$ to 10 equiv.) in ethanol/HEPES buffer $(\mathrm{pH}=7.42)(\mathrm{v} / \mathrm{v}$ 1.1). (c) ${ }^{2}$ 's $\mathrm{plot}^{2+}$ of $\mathrm{L}$ with (d) solution.

To evaluate the sensitivity of probe $\mathbf{L}$ towards $\mathrm{Cu}^{2+}$ in ethanol/HEPES buffer (v/v, 1:1), the titration experiments were performed via UV-vis absorption and fluorescence spectra. As depicted in Figure 3a, probe $\mathbf{L}$ exhibited a main absorption band at $440 \mathrm{~nm}$. With the increasing concentrations of $\mathrm{Cu}^{2+}$, the absorbance band at $440 \mathrm{~nm}$ gradually decreased accompanying with a blue shift. Meanwhile, two new absorption bands appeared at $390 \mathrm{~nm}$ and $480 \mathrm{~nm}$, demonstrating a new complex was formed between probe $\mathbf{L}$ and $\mathrm{Cu}^{2+}$. As expected, the fluorescence intensity of the emission band at $528 \mathrm{~nm}$ decreased continually along with 0-10.0 equiv of $\mathrm{Cu}^{2+}$ (Figure 3b). Further, the reversibility of copper complexation with probe $\mathbf{L}$ was confirmed by EDTA titration. As shown in Figure S2, the UV-vis absorbance and fluorescence spectra of $\mathbf{L}$ could be largely restored upon the addition of EDTA. The results demonstrated that the binding of probe $\mathbf{L}$ and $\mathrm{Cu}^{2+}$ was chemically reversible.

To further investigate the binding mode, Job’s plot and Benesi-Hildebrand plot analysis were performed (Figure 3c, S3 and S4). The results indicated that probe $\mathbf{L}$ binds to $\mathrm{Cu}^{2+}$ in a 2:1 stoichiometry. The binding constant of probe $\mathbf{L}$ and $\mathrm{Cu}^{2+}$ was calculated to be $8.5 \times 10^{4} \mathrm{M}^{-1}$ according to 
the Benesi-Hilderbrand equation. In addition, the limit of detection (LOD) of $\mathbf{L}$ towards $\mathrm{Cu}^{2+}$ was calculated to be $1.78 \mu \mathrm{M}^{29}$. As shown in Figure S5, the response time of $\mathbf{L}$ to $\mathrm{Cu}^{2+}$ was also investigated. The results indicated that probe $\mathbf{L}$ possesses fast response to $\mathrm{Cu}^{2+}$ in ethanol/HEPES buffer (v/v, 1:1).

Before further exploring its biological application, the two-photon action cross-section $(\Phi \sigma)$ of probe $\mathbf{L}$ was investigated. As manifested in Figure 3d, the maximum $\Phi \sigma$ of $\mathbf{L}$ was $29 \mathrm{GM}$ at $700 \mathrm{~nm}$. As shown in Figure S6, two-photon excited fluorescence spectra exhibited logarithmic plots of the fluorescence integral versus input power with a slope of 2.09 as the input laser power increased, indicating a two-photon absorption property and $\mathbf{L}$ is suitable for detecting $\mathrm{Cu}^{2+}$ by using two-photon microscopy technique.

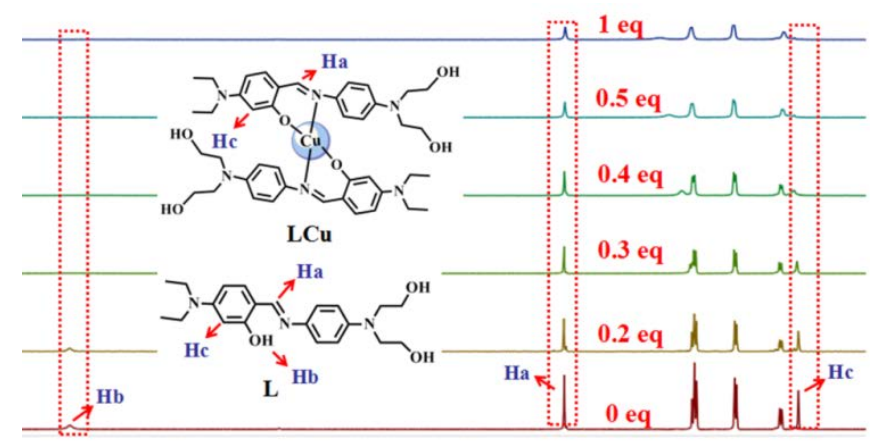

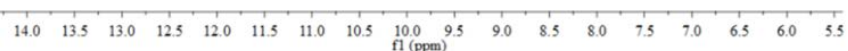

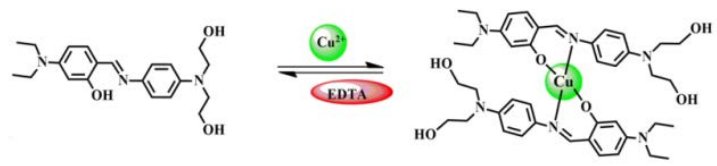

Figure $4{ }^{1} \mathrm{H}$ NMR spectra of $\mathrm{L}(0.01 \mathrm{M})$ upon titration with 0 equiv, 0.2 equiv, 0.3 equiv, 0.4 equiv, 0.5 equiv, 1 equiv of $\mathrm{Cu}\left(\mathrm{NO}_{3}\right)_{2}(0.1 \mathrm{M})$ in $\mathrm{d}_{6}$-acetone; proposed 2:1 complex formed between $\mathrm{L}$ and $\mathrm{Cu}^{2+}$.

\subsection{Mechanism studies}

To verify the above sensing mechanism, ${ }^{1} \mathrm{H}$ NMR titration spectra were carried out ${ }^{25,30-31}$. As we know, copper (II) almost universally causes peaks to disappear in ${ }^{1} \mathrm{H}$ NMR spectra upon complex formation due to its paramagnetic nature. As displayed in Figure 4, the $-\mathrm{OH}$ proton (Hb) signal and the aromatic ring proton (Hc) gradually decreased, simultaneously small changes were observed that the $-\mathrm{CH}=\mathrm{N}$ - proton $(\mathrm{Ha})$ signal at $8.60 \mathrm{ppm}$ with the addition of $\mathrm{Cu}^{2+}$. When the quality of $\mathrm{Cu}^{2+}$ increased to 0.5 equiv, the signal of Hc almost disappeared, the changes of which manifested that the $\mathrm{N}$ atom of $-\mathrm{CH}=\mathrm{N}$ - bond and the $\mathrm{O}$ atom of the phenolic hydroxyl may coordinate with the center $\mathrm{Cu}^{2+}$ by a 2:1 binding model, which was further confirmed by the mass spectra. As show in Figure S7, after the addition of $\mathrm{Cu}^{2+}$ to the solution, a new peak at $\mathrm{m} / \mathrm{z}=800.77$ corresponding to $[\mathrm{LCu}-3 \mathrm{H}]^{+}$appeared. Taken together, we proposed a plausible binding mode of probe $\mathbf{L}$ responses to $\mathrm{Cu}^{2+}$ (Figure 4).

To gain an insight into the photophysical property of $\mathbf{L}$ and LCu, TD-DFT calculations were carried out by Gaussian 09 program. The frontier molecular orbitals distributions and the calculated data were listed in Figure S7 and Table S3. As show in Figure S8, for free probe $\mathbf{L}$, the HOMO-1 and LUMO is mainly localized on the whole molecule, respectively, which indicated that the HOMO$1 \rightarrow$ LUOMO transition can be assigned as a $\pi-\pi^{*}$ transition. Upon the addition of $\mathrm{Cu}^{2+}$, two new absorption bands at $390 \mathrm{~nm}$ and $480 \mathrm{~nm}$ can be observed. For LCu, the distribution of HOMO-5 is mainly located on the 4(Diethylamino)salicylaldehyde moiety, and $\mathrm{C}=\mathrm{N}$ group. The HOMO-1 is primarily located on the one of free ligand with a small distribution on the copper (II) center. The LUMO+1 and LUMO+2 largely occupy the two different ligands. The lowest energy band calculated at 484 $\mathrm{nm}$, which mainly originates from $\mathrm{HOMO}-1 \rightarrow \mathrm{LUOMO}+2$ transitions, which can be assigned to the LLCT (ligand-toligand charge transfer) mixed with MLCT (metal-to-ligand charge transfer). The transition at $394 \mathrm{~nm}$ corresponds to the $\mathrm{HOMO}-5 \rightarrow \mathrm{LUMO}+1$, which can be assigned to the ICT (intramolecular charge transfer) mixed with LLCT. Accordingly, a turn-off fluorescent probe of sensing $\mathrm{Cu}^{2+}$ based on Schiff base derivative has been realized. 


\subsection{Biological application}

To explore the potential biological application of probe $\mathbf{L}$, the biocompatibility is essential to evaluate and the MTT assay was used to investigate its cytotoxicity. Figure S9 showed that after over $24 \mathrm{~h}$ of treated with probe $\mathbf{L}$, high cell viability was observed at the concentration from $5 \mu \mathrm{M}$ to $60 \mu \mathrm{M}$. The MTT assay results demonstrated that probe $\mathbf{L}$ exhibited low toxicity against living HepG2 cells and good biocompatibility, which can be served as a potential probe for living cell imaging.

As depicted in Figure 5, after incubation with probe $\mathbf{L}$ $(10 \mu \mathrm{M})$ for $30 \mathrm{~min}$, clear intracellular fluorescence in cytoplasm was observed in living cell imaging by confocal microscopy. However, the bright green fluorescence of live cells was disappeared when $\mathrm{Cu}^{2+}(20 \mu \mathrm{M})$ were added into the incubation solution. Then upon the addition of EDTA $(20 \mu \mathrm{M})$ for $30 \mathrm{~min}$, the fluorescence within cells was restored under the same optical window. These facts were in accordance with the sensing results obtained in the solution. Therefore, probe $\mathbf{L}$ could serve as an intracellular probe for detecting $\mathrm{Cu}^{2+}$ in living cells.
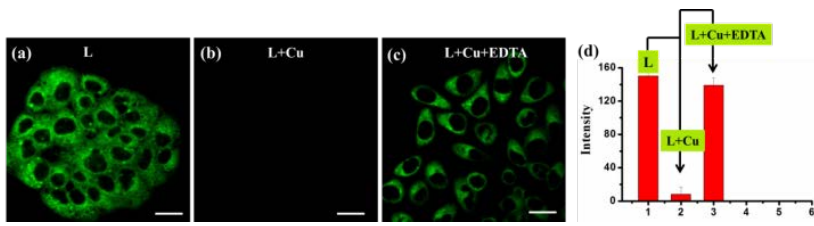

Figure 5 Confocal fluorescence images of HepG2 cells treated with $10 \mu \mathrm{M} \mathrm{L}$ for 30 min (a). (b) L treated HepG2 cells after 30 min labeled with $10 \mu \mathrm{M} \mathrm{Cu}\left(\mathrm{NO}_{3}\right.$ water solution. (c) LCu treated HepG 2 cells after 30 min labeled with $20 \mu$ EDTA water solution. (d) The relative fluorescence intensities of (a)-(c). Bar $=20$ $\mu \mathrm{m}$

To demonstrate the specific localization of probe $\mathrm{L}$ in living cells, a colocalization experiments were performed. ER tracker greed dye and Hoechst 33342 were used to costain HepG2 cells. As depicted in Figure 6, The colocalization imaging experiment unambiguously proved that probe $\mathbf{L}$ specifically localize in the endoplasmic reticulum with Pearson's coefficients $\mathrm{Rr}=0.93$, but no overlapping was observed with Hoechst 33342. It is noteworthy that endoplasmic reticulum is membrane-rich organelle, as probe $\mathbf{L}$ is lipophilic molecules because $\mathbf{L}$ has
$\mathrm{N}, \mathrm{N}$-azanediyldiethanol and $\mathrm{N}, \mathrm{N}$-diethylamine moiety, so we speculated that probe $\mathbf{L}$ could associate with lipophilic region within the cell. These result indicated that probe $\mathbf{L}$ was capable of targeting endoplasmic reticulum in living cells.

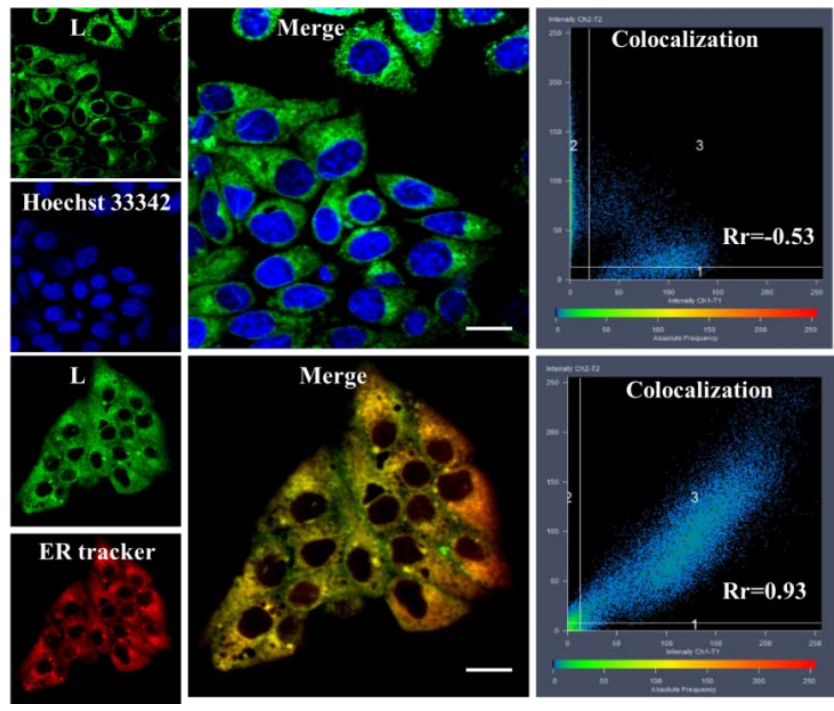

Figure 6 Determination of intracellular localization of $\mathbf{L}$ by confocal microscopy. HepG 2 cells were treated with $L(10 \mu \mathrm{M})\left(\lambda_{\text {ex }}=700 \mathrm{~nm}, \lambda_{\text {em }}=520-560 \mathrm{~nm}\right)$ for 30
min and then co-incubated with Hoechst 33342 and ER tracker for $30 \mathrm{~min}$ at 37 ${ }^{\circ} \mathrm{C}$, respectively. $\mathrm{Bar}=20 \mu \mathrm{m}$.

The cellular uptake mechanism of probe $\mathbf{L}$ was also studied. As shown in Figure 7, HepG2 cells were incubated with probe $\mathbf{L}$ at $4{ }^{\circ} \mathrm{C}$, the fluorescence can be still observed, revealing that probe $\mathbf{L}$ enter cells via a temperature-independent pathway. Pre-treatment of HepG2 cells with endocytosis inhibitors (chloroquine and $\mathrm{NH}_{4} \mathrm{Cl}$ ) exhibit no effect on the uptake of probe $\mathrm{L}$. The results revealed that probe $\mathbf{L}$ is membrane permeable and penetrates into the cells via a temperature-independent pathway, possibly passive infusion.

Considering an ideal cellular probe should operate in a certain $\mathrm{pH}$ range for biological applications. The effect of $\mathrm{pH}$ ranging from 4.0 to 10.0 on the one-photon fluorescence of probe $\mathbf{L}$ was investigated in HEPES buffer. Figure S10 displayed that the probe $\mathbf{L}$ was insensitive to $\mathrm{pH}$ in the range of 6.8-8.3, indicating that $\mathbf{L}$ is $\mathrm{pH}$ independent in typical physiological environments (6.87.4). As shown in Figure S11, the photostability of $\mathbf{L}$ was further investigated, and ER tracker was included as the 
control. During $\sim 300 \mathrm{~s}$, the relative fluorescence intensity of probe $\mathbf{L}$ remained $80 \%$, whereas only $40 \%$ fluorescence intensity of ER tracker was observed. The higher photostability of $\mathbf{L}$ makes it favorable for long-term realtime tracking.

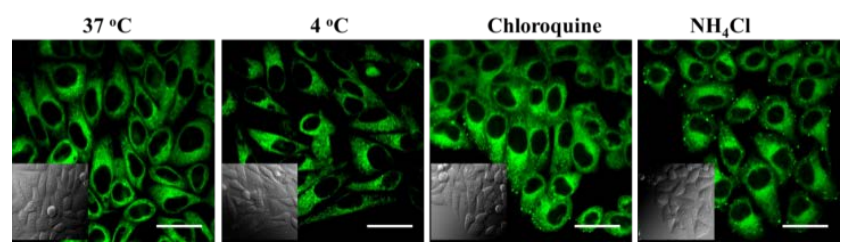

Figure 7 Effect of incubation temperature $\left(37^{\circ} \mathrm{C}\right.$ and $\left.4{ }^{\circ} \mathrm{C}\right)$, chloroquine $(50 \mu \mathrm{M}$ and $\mathrm{NH}_{4} \mathrm{Cl}(50 \mu \mathrm{M})$ on cellular uptake of $\mathbf{L}(10 \mu \mathrm{M})$ measured by confocal microscopy. Scale bar $=20 \mu \mathrm{m}$

\section{Conclusion}

In summary, a novel fluorescent probe $\mathbf{L}$ with high selectivity and sensitivity for sensing $\mathrm{Cu}^{2+}$ in an "on-offon” fluorescent switch was fabricated by using a simple one-step reaction. The mechanism has been investigated both experimentally and theoretically. Importantly, probe L exhibits low cytotoxicity, good photo-stability, and specificity to localize in endoplasmic reticulum, indicating probe $\mathbf{L}$ could serve as a tool to exploit potential functions of $\mathrm{Cu}^{2+}$ at subcellular levels. Therefore, we hope that this probe could play a crucial part in physiology and pathology science in the future research.

\section{Acknowledgment}

This work was supported by grants from the Natural Science Foundation of Anhui Province (1508085SMB208), Doctoral Startup Foundation of Wannan Medical College (wYRCQD201715), the Educational Commission of Anhui Province of China (KJ2016A788), the Swedish Government Strategic Research Area in Materials Science on Functional Materials at Linköping University (Faculty Grant SFOMat-LiU \# 2009-00971).

\section{References}

1 A.S. Murugan, N. Vidhyalakshmi, U. Rameshb and J. Annaraj. J. Mater. Chem. B, 2017, 5, 3195-3200.

2 X.Q. Chen, C.S. Lim, D.Y. Lee, S.Y. Lee, S.J. Park, H.M. Kim and Y.Y. Yoon. Biosens. Bioelectron., 2017, 91, 770-779.

3 Y. Li, M. Sun, K. Zhang, Y.J. Zhang, Y.H. Yan, K.P. Lei, L.J. Wu, H. Yu and S.H. Wang. Sensor. Actuat. B-Chem., 2017, 243, 3642.

4 Y. Yang, Y. Feng, Y.Z. Wang, F.Z. Qiu, X.L. Tang, G.L. Zhang and W.S. Liu. Sensor. Actuat. B-Chem., 2017, 253, 10551062.

5 W. Li, B. Fang, M. Jin and Y. Tian. Anal. Chem., 2017, 89, 2553-2560.

6 S.C. Dodani, S.C. Leary, P.A. Cobine, D.R. Winge and C.J. Chang. J. Am. Chem. Soc., 2011, 133, 8606-8616.

7 M.M. Guo, P.Y. Dong, Y. Feng, X.G. Xi, R. Shao, X.H. Tian, B.C. Zhang, M.Z. Zhu and X.M. Meng. Biosens. Bioelectron., 2017, 90, 276-282.

8 L. Banci, I. Bertini, S. Ciofi-Baffoni, T. Kozyreva, K. Zovo and P. Paulmaa. Nature., 2010, 465, 645-648.

9 L.K. Kumawat, N. Mergu, A.K. Singh and V.K. Gupta. Sensor. Actuat. B-Chem., 2015, 212, 389-394.

10 R.R. Crichton, D.T. Dexter and R.J. Ward. Coord. Chem. Rev., 2008, 252, 1189-1199.

11 R. McRae, P. Bagchi, S. Sumalekshmy and C.J. Fahrni. Chem. Rev., 2009, 109, 4780-4827.

12 A.X. Ding, Y.D. Shi, K.X. Zhang, W. Sun, Z.L. Tan, Z.L. Lu and L. He. Sensor. Actuat. B-Chem., 2018, 255, 440-447.

13 Y. Tachapermpon, S. Thavornpradit, A. Charoenpanich, J. Sirirak, K. Burgess and N. Wanichachev. Dalt. Trans., 2017, 46, 16251-16256.

14 X.L. Zheng, R.X. Ji, X.Q. Cao and Y.Q. Ge. Anal. Chim. Acta., 2017, 978, 48-54.

15 P. Kumar, R. Kaushik, A. Ghosh and D.A. Jose. Anal. Chem., 2016, 88, 11314-11318.

16 S. Y. Park, W. Kim, S.H. Park, Ji. Han, J. J. Lee, C. Kang and M. H. Lee. Chem. Commun., 2017, 53, 4457-4460.

17 L. Zeng, E. W. Miller, A. Pralle, E. Y. Isacoff and C. J. Chang. J. Am. Chem. Soc., 2006, 128, 10-11.

18 D. W. Domaille, L. Zeng and C. J. Chang. J. Am. Chem. Soc., 2010, 132, 1194-1195.

19 Y. Fan, Q. C. Feng, X. J. Jiang, H. Xu, M. Li and S. Q. Zang. Dalton. Trans., 2014, 43, 5815-5822.

20 Q. Zhang, X. H. Tian, H. Wang, Z. J. Hu, J. Y. Wu, H. P. Zhou, S Y. Zhang, J. X. Yang, Z. Q. Sun, Y. P. Tian and K. Uvdal. Sensor. Actuat. B-Chem., 2016, 222, 574-578.

21 H. Y. Liu, B. B. Zhang, C. Y. Tan, F. Liu, J. K. Cao, Y. Tan and Y. Y. Jiang. Talanta., 2016, 161, 309-319.

22 Y. Q. Cai, J. H. You, Z. Y. You, F. Dong, S. H. Du and L. Y. Zhang. Biosens. Bioelectron., 2018, 99, 332-337.

23 Z. J. Hu, J. W. Hu, Y. Cai, G. N. Wang, X. J. Zhang, K. Uvdal and H. W. Gao. J. Mater. Chem. B., 2014, 2, 4467-4472.

24 H.M. Kim and B.R. Cho. Chem. Rev., 2015, 115, 5014-5055.

25 L. Hu, H. Wang, B. Fang, Z.Y. Hu, Q. Zhang, X.H. Tian, H.P. Zhou, J.Y. Wu and Y.P. Tian. Sensor. Actuat. B-Chem., 2017, 251, 993-1000

26 C.H. Zhang, B.Z. Gao, Q.Y. Zhang, G.M. Zhang, S.M. Shuang and C. Dong. Talanta., 2016, 154, 278-283.

27 M.G. Ferlin, L.D. Via and O.M. Gia. Bioorg. Med. Chem., 2004 12, 771-777.

28 D.L. Ma, S. Lin, W.H. Wang, C. Yang and C.H. Leung. Chem Sci., 2017, 8, 878-889.

29 A.X. Ding, F. Tang, T. Wang, X.T. Tao and J.X. Yang. J. Chem Sci., 2015, 127, 375-382.

30 M. Q. Wang, K. Li, J. T. Hou, M. Y. Wu, Z. Huang and X. Q. Yu. J. Org. Chem., 2012, 77, 8350-8354. 
31 S. Sarkar, S. Roy, A. Sikdar, R. N. Saha and S. S. Panja. Analyst., 2013, 138, 7119-7126. 